\title{
Relações interpessoais durante o parto: percepções de adolescentes
}

Interpersonal relations during birth: perceptions of adolescents

Relaciones interpersonales durante el parto: percepciones de adolescentes

\section{Heitor Silva Biondi', Nalú Pereira da Costa KerberII, Diogo Henrique Tavares ${ }^{\mathrm{III}}$ Eliana Cardia de Pinho ${ }^{\mathrm{IV}}$, Bruna Goulart Gonçalves-Griespachv ${ }^{\mathrm{v}}$, Letícia Amico Marques ${ }^{\mathrm{VI}}$}

Resumo: Objetivo: conhecer a percepção das adolescentes acerca das relações interpessoais estabelecidas com os profissionais de um Centro Obstétrico. Método: estudo qualitativo exploratório descritivo. Foram entrevistadas 62 adolescentes que tiveram filho em um Hospital Universitário do sul do Brasil. Os dados foram analisados por meio da Análise de Conteúdo, buscou-se visualizar os diferentes papéis profissionais descritos por Peplau. Resultados: o relacionamento interpessoal estabelecido com interação baseada no respeito, cordialidade, paciência, solicitude, presença constante, disposição para responder aos questionamentos e ações para transmitir tranquilidade e calma são aspectos satisfatórios. Porém, o distanciamento, desinformação, desrespeito e hostilidade também despontaram. O surgimento de elementos negativos parece estar ligado às posturas pessoais dos profissionais. Considerações Finais: o relacionamento interpessoal não é compreendido como parte fundamental da assistência ao parto, deixando de ser explorado em sua plenitude enquanto parte do cuidado, permanecendo em segundo plano e compartimentalizando a assistência ao parto.

Descritores: Adolescente; Relações profissional-paciente; Parto humanizado; Enfermagem

Abstract: Aim: to know the perception of the adolescents about the interpersonal relations established with the professionals of an Obstetric Center. Method: descriptive exploratory qualitative study. Sixty-two teenagers who had a child in a University Hospital in southern Brazil were interviewed. The data were analyzed through Content

\footnotetext{
${ }^{\text {I }}$ Enfermeiro. Doutorando em Enfermagem. Hospital Universitário Dr. Miguel Riet Correa Jr. Universidade Federal do Rio Grande, Integrante do Grupo de Pesquisa Viver Mulher. Rio Grande, Rio Grande do Sul, Brasil. E-mail: enf.heitor@gmail.com ORCID 0000-0002-7175-9538

II Enfermeira. Doutora em Enfermagem. Universidade Federal do Rio Grande, Líder do Grupo de Pesquisa Viver Mulher. Rio Grande, Rio Grande do Sul, Brasil. E-mail: nalukerber@gmail.com ORCID 0000-0001-9947-4190

${ }^{\text {III }}$ Enfermeiro. Doutorando em Enfermagem. Universidade Federal de Pelotas. Integrante do Grupo de Pesquisa em Saúde Metal e Coletiva. Pelotas, Rio Grande do Sul, Brasil. E-mail: enf.diogotavares@gmail.com ORCID 0000-0002-0961-6421

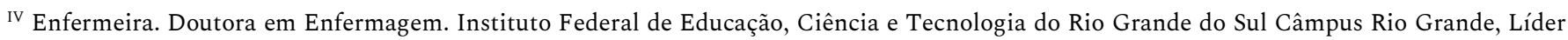
do Grupo de Estudos e Pesquisas em Saúde e integrante do Grupo de Pesquisa Viver Mulher. Rio Grande, Rio Grande do Sul, Brasil. E-mail: gama@vetorial.net ORCID 0000-0003-2523-9651

${ }^{\vee}$ Enfermeira. Doutora em Ciências da Saúde. Universidade de São Paulo, Integrante do Grupo de Pesquisa Viver Mulher. Hamburgo, Alemanha. E-mail: brunaggoncalves@gmail.com ORCID 0000-0001-7102-1093

VI Enfermeira. Doutoranda em Enfermagem. Universidade Federal do Rio Grande, Integrante do Grupo de Estudo e Pesquisa em Família, Enfermagem e Saúde. Rio Grande, Rio Grande do Sul, Brasil. E-mail: enfle@outlook.com ORCID 0000-0002-0203-0946
} 
Analysis, and we sought to visualize the different professional roles described by Peplau. Results: the interpersonal relationship established with interaction based on respect, cordiality, patience, solicitude, constant presence, willingness to respond to questions, and actions to convey tranquility and calm are satisfactory aspects. However, detachment, disinformation, disrespect and hostility also emerged. The emergence of negative elements seems to be linked to the personal postures of professionals. Final Considerations: interpersonal relationships are not understood as a fundamental part of childbirth care, and are no longer fully explored as part of care, remaining in the background and compartmentalizing childbirth care.

Descriptors: Adolescent; Professional-Patient Relations; Humanizing Delivery; Nursing

Resumen: Objetivo: conocer la percepción de las adolescentes sobre las relaciones interpersonales establecidas con los profesionales de un Centro Obstétrico. Método: estudio cualitativo, exploratorio, descriptivo. Fueron entrevistadas 62 adolescentes que tuvieron hijo en un Hospital Universitario del sur de Brasil. Los datos fueron analizados por medio de análisis de contenido, con el cual se buscó visualizar los diferentes papeles profesionales descriptos por Peplau. Resultados: la relación interpersonal basada en el respeto, cordialidad, paciencia, solicitud, presencia constante, disposición para responder a los cuestionamientos y acciones para transmitir tranquilidad y calma son aspectos satisfactorios. Pero, el distanciamiento, desinformación, falta de respeto y hostilidad también fueron identificados. El surgimiento de esos elementos negativos puede estar relacionado a las posturas personales. Consideraciones finales: la relación interpersonal no es entendida como fundamental en la asistencia al parto, deja de ser explotada en su plenitud, como parte del cuidado, permanece en segundo plan y segmenta la asistencia al parto.

Descriptores: Adolescente; Relaciones Profesional-Paciente; Parto humanizado; Enfermería

\section{Introdução}

O presente estudo está centrado nas relações interpessoais vivenciadas por parturientes adolescentes no ambiente de assistência ao nascimento. Esse espaço é permeado de emoções e sentimentos, muitas vezes conflituosos, por parte da mulher e de sua família, que perpassam desde a alegria pela chegada de um filho, ao enfretamento da dor, das angústias e dos medos diante deste processo. Além disso, a parturição pode ser acompanhada por diversos níveis de simbolização, como imaginar a má-formação do filho ou a sua não resistência à dor, proporcionando um caráter ainda mais assustador e negativo para este momento. ${ }^{1}$

No entanto, a vivência do parto, considerada tão desafiadora, pode ser facilitada por meio de uma relação humanizada do cuidado. A humanização ancora-se no dever dos profissionais de saúde de receber com dignidade a mulher, seus familiares e o recém-nascido. Para isto, há necessidade de 
uma atitude ética e solidária, pautada também nas relações interpessoais, de modo a criar um ambiente acolhedor e promotor de tranquilidade e segurança. ${ }^{2}$

Todos estes fatores parecem ser mais acentuados na mulher adolescente, em virtude da fase de desenvolvimento e transformações em que esta se encontra, pela pouca maturidade biopsicossocial e das possíveis implicações trazidas pelo evento para ela e sua família, que podem diferir das mulheres de outras faixas etárias. No entanto, os aspectos relacionados com a assistência ao parto de adolescentes, para além das particularidades biopsicossociais e fisiológicas, ainda são pouco compreendidos, ${ }^{3}$ o que exige o desenvolvimento de estudos que visem preencher tal lacuna do conhecimento.

Buscando a melhoria da assistência prestada às mulheres no ciclo-gravídico puerperal, o Ministério da Saúde lançou, no ano de 2000, o Programa de Humanização do Pré-Natal e Nascimento (PHPN), complementado, mais recentemente, pela Rede Cegonha, objetivando reorganizar a assistência, vinculando-a ao pré-natal, parto e puerpério, ampliando e garantindo o acesso e a qualidade, com a realização de um conjunto mínimo de procedimentos, visando a autonomia e o empoderamento da mulher. Estes programas de humanização voltados ao ciclo gravídico-puerperal têm seu foco principal na mulher e no resgate da dignidade durante o processo parturitivo, buscando a adoção de práticas humanizadas, centradas no ser humano em sua complexidade, transformando a atenção prestada durante a gestação, o parto e o puerpério, considerando as particularidades de cada mulher, o que inclui as trazidas pelos diferentes momentos etários em que se vive o parto. $^{2}$

A efetivação da assistência humanizada ao parto é um tema de crescente interesse, em virtude das inúmeras implicações que este momento pode trazer aos envolvidos, com ênfase especial às mulheres que vivenciam este momento ainda durante a adolescência. Os sentidos, os conteúdos e as finalidades dessa forma de cuidado consistem em um desafio, pois implicam em 
Relações interpessoais durante o parto: percepções de adolescentes | 4

que os trabalhadores da saúde estejam preparados para atender à gestante e seus acompanhantes, respeitando os verdadeiros significados desse momento. ${ }^{4}$

Todavia, aspectos subjetivos do ser humano estão envolvidos na efetivação do processo de humanização da assistência obstétrica, necessitando de uma abordagem centrada na pessoa e nas relações interpessoais. ${ }^{3,5}$ Nesse sentido, visualiza-se a contribuição da teorista da enfermagem Hildegard E. Peplau ${ }^{6}$ que, desde 1952, advoga pela importância das relações interpessoais no processo de cuidado da enfermagem.

A teorista visualizou o cuidado como um processo interpessoal em que o profissional assume diferentes papéis superpostos e relacionados: o de estranho, o de recurso, o de professor, o de substituto, o de conselheiro e o de líder. Ao assumir cada um destes papéis, o profissional aprofunda as relações interpessoais e instrumentaliza o usuário. ${ }^{6}$

Destarte, considera-se que as relações interpessoais contribuem para a vivência do parto de maneira humanizada, especialmente quando pautadas em uma relação menos autoritária e mais solidária. E, ainda, quando esta interação é capaz de valorizar a subjetividade de cada parturiente, resgatando o vínculo e reconhecendo o parto como experiência singular e peculiar para cada mulher e, por isso, especial e com diferentes sentimentos e necessidades, ${ }^{7}$ o que inclui a dimensão das particularidades da mulher adolescente.

A literatura revela distintos elementos envolvidos nas relações interpessoais durante o parto, tanto os que facilitam como aqueles que obstaculizam a humanização. Entre os aspectos pode-se citar: a escuta e o acolhimento como recursos de significativa importância na assistência ao parto; ${ }^{5}$ o distanciamento entre o profissional e a parturiente, sem interação no sentido do afeto, aproximação e do cuidar verdadeiro; ${ }^{8}$ as informações insuficientes recebidas e a relação hierarquizada durante o parto. ${ }^{9}$ Não obstante, mesmo as mulheres adolescentes representando mais de $20 \%$ dos parturientes do país, conforme explicitado pelo Ministério da Saúde, ${ }^{2}$ são encontradas poucas pesquisas que adentrem a especificidade das interações 
estabelecidas durante a assistência a este público e que estejam alicerçadas em um referencial teórico sobre relações interpessoais.

Diante do panorama apresentado, questionou-se: quais as percepções das parturientes adolescentes acerca das relações interpessoais estabelecidas com os profissionais que atuam no Centro Obstétrico? Motivado por este questionamento, o estudo tem como objetivo conhecer a percepção de adolescentes acerca das relações interpessoais estabelecidas com os profissionais que atuam em um Centro Obstétrico.

\section{Método}

Estudo vinculado à macropesquisa intitulada: “Atenção humanizada ao parto de adolescentes”, desenvolvida em um Hospital Universitário (HU) no extremo sul do Brasil. A macropesquisa possui características censitárias e foi realizada no período de junho a outubro de 2014, com 62 parturientes adolescentes que tiveram o parto vaginal ou cesáreo no HU, não havendo perdas ou recusas.

O desenvolvimento deste manuscrito ancora-se na etapa qualitativa, exploratória e descritiva da macropesquisa. Esta etapa foi efetivada por meio de entrevistas que ocorreram na Unidade de Internação Obstétrica, durante as últimas 24 horas da internação das adolescentes no pós-parto, tendo duração média de 15 minutos. Seguiram-se como critérios de inclusão: apresentar condições físicas e psíquicas de participarem da pesquisa, não apresentar complicações clínicas no pós-parto e o recém-nascido não ter morrido no pós-parto ou não ser natimorto.

A investigação consistiu-se da pergunta: "como você considera que foi a relação da equipe com você e seus familiares?”. As entrevistas foram gravadas, e, posteriormente, transcritas. Para o tratamento dos dados foi utilizada a Análise de Conteúdo. ${ }^{10}$

Durante a exploração do material buscou-se estabelecer uma correlação entre os achados e a literatura científica acerca da temática, bem como se tentou visualizar os diferentes papéis 
que podem ser assumidos pelos profissionais de saúde em sua relação com as usuárias, descritas por Peplau, ${ }^{6}$ no sentido de compreender alguns aspectos da interação entre os profissionais de saúde e seus objetos do cuidado: estranho, recurso, professor, substituto, conselheiro, líder. Acredita-se que, embora a teoria explicitada seja de enfermagem, as considerações utilizadas também são aplicáveis às interações entre os demais profissionais de saúde e usuários dos serviços de saúde em geral.

O papel de estranho é desempenhado no contato inicial da usuária com o profissional implicando em uma aceitação entre eles, em uma relação de respeito e interesse. O de recurso é quando se oferecem informações para compreensão das situações e o profissional proporciona respostas específicas aos questionamentos da usuária. O de professor é quando se compartilham conhecimentos e o ensino se processa a partir do que a usuária já conhece e se desenvolve em torno do seu interesse. ${ }^{6}$

No papel de substituto, a usuária considera inconscientemente o profissional como uma pessoa que pode simbolizar uma figura familiar. O papel de conselheiro é desempenhado quando se auxilia a usuária ou outra pessoa no reconhecimento, aceitação, enfrentamento e solução de problemas. E o de líder é desenvolvido por meio da capacidade do profissional de sentar-se junto a usuária, observar, compreender como uma situação pode afetá-la, analisar o que sucede em seu íntimo e apreciar o desenvolvimento da relação interpessoal entre ambos. ${ }^{6}$

A macropesquisa à qual este estudo está vinculado obteve a aprovação do Comitê de Ética em Pesquisa, da Universidade Federal do Rio Grande, em 14 de maio de 2008, sob o № 31/2008 e Certificado de Apresentação para Apreciação Ética № 23116.001158/2008-61. As entrevistas com as adolescentes foram realizadas após serem esclarecidos os objetivos e métodos, efetuado o convite à participação e procedida a assinatura destas em Termo de Assentimento e de seu responsável legal, no Termo Consentimento Livre e Esclarecido, sendo estas identificadas pela letra “A”, seguida de um número. 
7 I Biondi HS, Kerber NPC, Tavares DH, Pinho EC, Gonçalves-Griespach BG, Marques LA

Os dados da macropesquisa foram retornados aos gestores do $\mathrm{HU}$ e trabalhadores da maternidade e Centro Obstétrico (CO), por meio de reuniões e capacitações aos mesmos. Esta etapa culminou na realização do II Simpósio Internacional de Humanização da Atenção Obstétrica e Neonatal, em que foram realizados distintos cursos voltados à equipe multiprofissional atuante na área materno infantil da instituição onde foi realizado o estudo, fomentando melhorias na qualidade da assistência obstétrica.

\section{Resultados}

As participantes do estudo apresentavam-se na faixa etária de 14 a 19 anos, com predominância da idade de 18 anos (40,32\%); 41,92\% tinham menos de sete anos de estudo, e $55,73 \%$ tiveram o parto vaginal. As participantes deste estudo apresentaram considerações diferentes no que concerne às relações interpessoais dos profissionais de saúde com as parturientes e familiares. Cabe ressaltar que aspectos positivos e negativos despontaram dos dados e que, por se entender a importância que estes elementos assumem no processo relacional como parte do cuidado, eles serão trabalhados em categorias distintas. Todavia, o conteúdo explicitado nas falas não revelou particularidades que estivessem associadas a via de parto, sendo os elementos trazidos pelas adolescentes que tiveram parto vaginal e parto cesáreo apresentados conjuntamente nas categorias.

\section{Aspectos desencadeadores de satisfação nas adolescentes}

Para algumas adolescentes, a relação interpessoal com os profissionais de saúde que prestaram assistência ao parto é considerada satisfatória. Este tipo de relação despontou por ser baseada no respeito e na partilha de informação, o que proporcionou o estabelecimento do vínculo. 
Os aspectos que permeiam a relação interpessoal com a equipe, valorizados pelas parturientes, foram a paciência do profissional, as ações do mesmo para transmitir tranquilidade e calma, bem como sua disposição para responder aos questionamentos e fornecer informações às parturientes acerca do trabalho de parto. Estes elementos revelam-se significativos para que as mesmas consigam compreender o que está acontecendo com seu corpo e com o seu filho ao longo do trabalho de parto, evento este possivelmente pouco conhecido e entendido, por se tratar de adolescentes.

Eles me trataram bem, tudo que eu perguntava para eles respondiam direito, explicavam tudo com calma. (A3)

Comigo foi muito boa [...] eles ficavam o tempo todo me tranquilizando, me acalmavam, conversavam comigo, explicavam o que estava acontecendo, diziam o que fazer. (A26)

Os resultados do estudo revelam que a presença constante e a solicitude do profissional são aspectos relevantes para que a relação interpessoal se concretize de forma satisfatória. Questionar a adolescente sobre seu bem-estar e suas necessidades foram ações que transformaram positivamente a interação entre o profissional e a parturiente e permitiram que o vínculo fosse aprofundado. Este constructo torna-se significativo à medida que traz à adolescente, os elementos necessários para que esta sinta-se segura e amparada emocionalmente e fisicamente pela equipe, mesmo estando em uma vivência, um contexto, um local e diante de profissionais, até então desconhecidos. Permite a instrumentalização da mesma para participar mais ativamente deste processo, podendo reduzir seus medos e angustias, que são potencializadas pela pouca maturidade biopsicossocial.

Eles me deram toda a atenção, todas as vezes que eu precisei me ajudaram, tudo que eu precisei eles me ajudaram. (A40) 
9| Biondi HS, Kerber NPC, Tavares DH, Pinho EC, Gonçalves-Griespach BG, Marques LA

Eles me trataram 'tri' bem e se eu precisasse de alguma coisa era para falar. Estava toda hora aparecendo alguém e perguntando como é que eu estava. (A48)

Os depoimentos de algumas adolescentes revelam que antes de serem internadas, tinham expectativas negativas para o relacionamento com a equipe, o que não se concretizou efetivamente. Esta pré-concepção negativa parece estar associada ao receio de receber um tratamento coercitivo e inapropriado da equipe multiprofissional, em virtude de serem adolescentes experienciando a vivência no parto, bem como o zelo e a busca de informações de sua família não fossem acolhidos com respeito.

A minha mãe bateu [na porta do $\mathrm{CO}$, buscando informações] várias vezes. $\grave{A} s$ vezes eles [os profissionais de saúde] se estressam, mas não foi o que aconteceu. (A5)

Foram muito atenciosos. Por ser nova, eu senti medo que eles me deixassem ‘sofrer até o último’. (A54)

O processo interacional positivo da equipe atuante no $\mathrm{CO}$ com os familiares, também foi valorizado pelas adolescentes. Os profissionais demonstraram disponibilidade para fornecer informações, adotando uma postura solícita e respeitosa. Tal aspecto é de fundamental importância, considerando que os momentos de interação dos profissionais que estão prestando a assistência ao parto com familiares das adolescentes que se encontram fora do CO, permitem a tranquilização da família acerca do processo parturitivo e das demandas relacionadas à especificidade etária destas parturientes.

A toda hora eles [profissionais de saúde] estavam indo lá conversar com ele [familiar], dar notícias, explicar o que estava acontecendo. (A42)

Eles [profissionais de saúde] deram notícias para eles [familiares], deixaram informados do que estava acontecendo. (A1) 
Eles nos trataram muito bem. Pelo que a minha mãe falava, em nenhum momento foram grosseiros e toda hora iam dizer como eu estava, isso foi ótimo. (A5)

\section{Aspectos desencadeadores de insatisfação nas adolescentes}

Para algumas adolescentes, o relacionamento interpessoal com os profissionais de saúde que prestaram a assistência foi pontuado por aspectos negativos. As participantes demonstram que a ausência dos profissionais em alguns momentos lhes confere a sensação de abandono e o afloramento sentimentos negativos, especialmente quando a presença deles só se efetiva durante a realização de procedimentos.

Eles [profissionais da saúde] te deixam muito sozinha lá, esquecem de ti, só lembram na hora dos exames. (A21)

Acho que foi regular porque não tinha ninguém comigo, eles me deixavam sozinha. (A34)

As falas demonstram, também, a desaprovação da postura adotada, bem como do tratamento dispensado por alguns profissionais diante das necessidades das adolescentes. Estas se materializaram por meio de condutas que buscavam coibir manifestações relacionadas a dor, suscitando sentimentos de desamparo e insegurança, desvalorizando os significados desta vivência às adolescentes, bem como sua vulnerabilidade.

Eles [profissionais da saúde] são muito grossos, a gente pergunta uma coisa e eles fazem uma 'tempestade num copo d'água'. Sempre é a gente que faz fiasco. (A18)

Eles não tratam o lado psicológico. Disseram: não grita, é fiasco. (A20)

Não gostei muito da doutora, ela foi grossa comigo. (A31)

Não me senti à vontade, me senti insegura e exposta [...]. (A62) 
11 I Biondi HS, Kerber NPC, Tavares DH, Pinho EC, Gonçalves-Griespach BG, Marques LA

Além disto, para algumas delas, a insatisfação esteve pautada nos comentários feitos pelos profissionais durante o parto, bem como no comportamento destes durante os momentos em que não estavam realizando assistência direta a elas.

Não vou te mentir, não gostei muito do atendimento [...] eu estava 'louca' de dor em cima da cama [...] e eles estavam tudo lá de risada, não estavam mostrando respeito pelas pessoas que estavam ali. (A2)

Eles foram muito estúpidos, não tiveram muito cuidado comigo. Tinha uma médica que dizia: 'estás com dor ou não?(A17)

Tenho queixa só da doutora, ela falava de mim: 'fizeste, agora vai ter que sair' [...] não respeitavam, ficavam vendo televisão, dando risadas [...]. (A51)

Outro fator de insatisfação está posto no relacionamento dos profissionais com os acompanhantes das parturientes, pela não partilha de informações acerca da evolução do seu trabalho de parto, bem como pela postura hostil de alguns profissionais.

[...] eu estava ganhando e não explicaram para o meu familiar, foram meio ignorantes. (A7)

Os meus familiares necessitavam de mais informação e queriam ser melhor recebidos. $(\mathrm{A} 45)$

[...] para dar informação para minha família foi péssimo. A enfermeira ou a médica, eu não sei, iam lá e não davam a informação direito, aí eles [familiares] não sabiam o que estava acontecendo comigo. (A58) 


\section{Discussão}

O conjunto dos dados analisados surpreende por apresentar significativas discrepâncias. Estas são evidenciadas nas diferentes descrições das relações interpessoais ocorridas durante o parto das adolescentes, bem como nas questões ligadas a humanização da assistência que vêm sendo apregoadas pelo Ministério da Saúde.

Diferentes aspectos permeiam o relacionamento interpessoal das adolescentes com os profissionais de saúde. Neste sentido, a satisfação das usuárias frente aos serviços de saúde está diretamente ligada ao estreitamento do vínculo existente entre elas e os profissionais. ${ }^{11} \mathrm{~A}$ construção de vínculo, enquanto referência e relação de confiança entre os profissionais e os familiares ${ }^{9}$ pode amenizar as percepções negativas e as experiências dolorosas, bem como auxiliá-los no enfrentamento do medo e da angústia, ${ }^{12}$ elementos estes que podem ser ainda mais exacerbados por tratarem-se de adolescentes.

O estabelecimento do vínculo se processa de forma gradual, enquanto o profissional de saúde assume os papéis descritos por Peplau, ${ }^{6}$ a fim de auxiliar a usuária no enfrentamento da situação vivenciada e, muitas vezes, não planejada ou desejada pela adolescente. Iniciado o primeiro contato entre os sujeitos, o profissional de saúde assume o papel de Estranho, ${ }^{6}$ que implica em um processo de aceitação da usuária pelo profissional de saúde e vice-versa.

Se a relação interpessoal se processa de maneira positiva enquanto o profissional de saúde atua como Estranho, ${ }^{6}$ o surgimento do vínculo entre estes se torna consequência do processo de aceitação. O sucesso do estabelecimento deste papel torna-se definidor da forma como irá se desenvolver o relacionamento interpessoal. Assim sendo, caso a atuação como Estranho não se desenvolva plenamente, pode-se inferir que toda a relação poderá estar comprometida. ${ }^{6}$ Isto ocorre em virtude da ausência do vínculo e confiança, necessários a humanização da assistência propiciada às adolescentes. As transformações físicas e psíquicas possuem grande influência nas suas interações sociais, o que pode levar ao afloramento e 
13 I Biondi HS, Kerber NPC, Tavares DH, Pinho EC, Gonçalves-Griespach BG, Marques LA

intensificação de medos, receios e angustias relacionados ao parto, e dificultar a aproximação do profissional com a parturiente.

Enquanto o profissional vivencia o papel de Estranho, ${ }^{6}$ busca aprofundar a relação interpessoal entre ele e a parturiente, a fim de estabelecer uma relação de confiança que permita contribuir para o enfrentamento do parto. Para que isso ocorra, o respeito precisa tornar-se o guia para a relação interpessoal. ${ }^{3,8-9,13}$ Ressalta-se que o processo interacional que tem como premissa o respeito, propicia o aprofundamento do acolhimento, enquanto postura ética, e do vínculo. Cabe a ressalva de que a pouca maturidade psicoemocional e o desconhecimento dos contextos e práticas relacionados a parturição, podem fazer com que as adolescentes minimizem ou maximizem elementos do processo interacional que tenham características (des)respeitosas.

Faz-se necessário que o olhar esteja direcionado para a compreensão do sujeito, entendendo-o como um ser ainda em desenvolvimento e, por isso, muitas vezes mais vulnerável, na tentativa de estabelecer com ele uma relação de empatia e ajuda, o que pode amenizar a situação vivenciada. Neste contexto, diferentes autores trazem a partilha de informações como destaque para que o

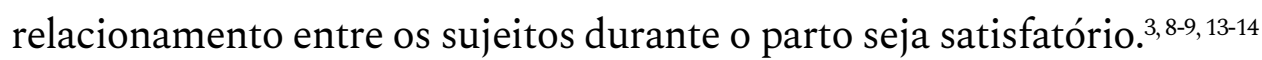

Nesse ínterim, o profissional pode assumir o papel de Recurso, ${ }^{6}$ caracterizado pela partilha de informações para compreensão das situações em que o profissional proporciona respostas específicas aos questionamentos e anseios das usuárias. Esta dimensão pode materializar-se de modo muito singular nas adolescentes, visto que sua pouca maturidade biopsicossocial tende a suscitar demandas diferenciadas em relação a mulheres ou outras faixas etárias.

A disponibilidade do profissional para transmitir informações também aos acompanhantes e a frequência em que esta ação ocorre, além da cordialidade, delicadeza, paciência dos profissionais, 3, 5, 8-9, 14 e da escuta, ${ }^{9}$ proporcionam à interação um papel agregador. Esta conjectura tende a promover a participação ${ }^{15}$ e a autonomia dos sujeitos. 
No tocante a efetivação do processo relacional, a comunicação se manifesta como instrumento norteador. Destarte, para o atendimento das necessidades das mulheres ainda na adolescência, o profissional deve desenvolver a habilidade de comunicar-se, sendo esta uma ação planejada de forma individualizada, não se realizando somente de forma intuitiva e por impulsos, para assim, promove ações de cuidado mais abrangentes, ${ }^{16}$ permitindo que este assuma os devidos papéis nos momentos propícios. Nesta perspectiva, o planejamento e execução da comunicação devem incluir os momentos em que esta se materializa de modo indireto, ou seja, quando o profissional está realizando outra atividade que não abarca o processo interacional direto com a parturiente ou sua família porém, sua presença, atuação e comportamento, permanecem sendo percebidos e emitindo algum tipo de mensagem.

Ao estabelecer uma comunicação efetiva com a parturiente adolescente e ao utilizá-la para compartilhar conhecimentos sobre uma necessidade ou interesse da mesma, de forma simples e compreensível para ela, o profissional assume o papel de professor. Enquanto neste papel, o processo de ensino proporcionado pelo profissional avança a partir do que a usuária já conhece e se desenvolve em torno do seu interesse. ${ }^{6}$ Neste sentido, as adolescentes revelam que foram orientadas acerca da evolução do trabalho de parto e como deveriam proceder nos distintos momentos desse processo de modo a facilitá-lo.

Entretanto, muitas vezes os profissionais não associam a este momento atitudes que aprofundem o relacionamento, deixando de explorar todos os aspectos da comunicação no processo relacional. Neste contexto, ao aproximar-se das usuárias em um processo de comunicação, os profissionais utilizam este momento para partilhar somente informações específicas sobre o estado clínico delas ou para solicitação de espaço para realização de procedimentos, desconsiderando as potencialidades deste momento para tornar a vivência do parto pela adolescente mais humanizado. ${ }^{16}$ 
15 I Biondi HS, Kerber NPC, Tavares DH, Pinho EC, Gonçalves-Griespach BG, Marques LA

Outros aspectos relacionados à satisfação nas relações interpessoais têm destaque nos depoimentos das adolescentes, também encontrados em outros estudos envolvendo a temática, como a presença constante do profissional, ${ }^{5,8,14,17}$ sua solicitude, e a valorização das necessidades da adolescente durante o trabalho de parto. ${ }^{9}{ }^{17-18}$ No contexto deste estudo, esse tipo de relação de proximidade mostra que o profissional de saúde pode assumir o papel de substituto, ${ }^{6}$ quando a usuária considera, mesmo que inconscientemente, o profissional como uma pessoa que simboliza uma figura familiar, que lhe conforta, incentiva e valoriza durante o parto. Esta atuação pode ser ainda mais significativa para parturientes adolescentes, uma vez que a pouca maturidade emocional podem torná-las ainda mais dependentes da presença do profissional para sentirem-se seguras.

Diante da valorização de suas necessidades pelo profissional, a figura passiva que é conferida à parturiente adolescente deixa de existir. Neste contexto, a mulher ganha voz, e tem sua participação e autonomia assegurados. Cabe ressaltar que estes mesmos elementos podem ser considerados como permeando o papel de conselheiro, ${ }^{6}$ no momento em que o profissional auxilia a usuária no reconhecimento, aceitação, enfrentamento e solução de problemas.

Reitera-se que a hospitalização e o ambiente em que o parto se processa trazem intenso desconforto e insegurança para as usuárias, ainda mais para as adolescentes que, em virtude de sua pouca idade, tendem a desconhecer as práticas e realidades deste contexto. Diante disto, os profissionais de saúde devem fazer uso de estratégias objetivando uma melhor interação, por meio de atitudes de sensibilidade, aceitação e empatia. A capacidade do profissional de permanecer junto aos outros sujeitos, compreender como uma situação pode afetá-los, analisar o que sucede em seu íntimo e apreciar o desenvolvimento da relação interpessoal, buscando maneiras de auxiliá-los neste processo, leva a pensar no papel de líder. ${ }^{6}$

O cuidado e o conforto que serão oferecidos para a parturiente durante o parto tornam esta experiência menos traumática. Isto se dá porque a mulher não teme apenas a dor do parto, 
mas, também, sente medo na expectativa pelos cuidados que receberá, já esperando um atendimento impessoal e distante. ${ }^{14}$ Os dados encontrados corroboram com esta afirmação, e demonstram que as adolescentes esperavam um relacionamento pior do que o encontrado. Ao mesmo tempo, têm a noção e compreensão que o mesmo ainda não é o ideal.

As expectativas negativas podem ser oriundas de experiências anteriores das próprias parturientes adolescentes ou de pessoas conhecidas, ou estarem ligadas a aspectos familiares e culturais, representando a atribuição de elementos negativos ao parto e ao relacionamento estabelecido com os profissionais durante o mesmo. Tal expectativa pode estar ligada, também, ao fato de serem adolescentes, e compreenderem que a maternidade nesta fase da vida pode não ser esperada socialmente, o que tornaria a postura do profissional hostil.

Não somente as expectativas frustradas podem propiciar relações conflituosas. Porém, a falta de conhecimento e preparo das parturientes para enfrentar o processo de parturição, bem como a falta de sensibilidade dos trabalhadores aparecem como elementos motivadores de processos interacionais negativos com maior magnitude para as adolescentes. ${ }^{3}$ Neste sentido, é possível identificar diferentes elementos que tornam o relacionamento interpessoal insatisfatório para as parturientes, os quais também já foram destacados em diversos estudos, como o desrespeito ${ }^{8-}{ }^{9},{ }^{13}$, o isolamento e o abandono $^{8,13,17}$, a impaciência, ${ }^{8}$ a falta de atenção e a indiferença. ${ }^{8,19}$

Nas falas de muitas das adolescentes há a demonstração de que, durante o parto, o profissional assume o controle e coloca-se como ator principal. Nesta perspectiva, o profissional, como detentor do saber científico, atenua a participação da mulher nos processos decisórios acerca do seu corpo, e impede o exercício de sua autonomia durante o trabalho de parto. Tal postura possibilita que o profissional assuma o papel de líder negativo que, ao invés de empoderar as mulheres, busca somente sua submissão.

Os resultados deste estudo mostram que, em muitas situações, as relações parecem se processar predominantemente durante a realização de um procedimento técnico, 
17 I Biondi HS, Kerber NPC, Tavares DH, Pinho EC, Gonçalves-Griespach BG, Marques LA

materializando uma ação caracterizada pelo afastamento interacional e emocional entre adolescentes e profissionais. Neste momento, a relação vertical é reafirmada pela postura do profissional, o que cria uma barreira para a aproximação dos sujeitos, e acentua o distanciamento entre ambos. ${ }^{8}$

As relações caracterizadas por grandes desequilíbrios de poder podem ser qualificadas como desumanas. Estas procedem quando o lado poderoso reduz o outro a situação de objeto, manipulando-o em função dos seus interesses e desejos, também desconsiderando interesses e desejos do outro..$^{20}$

O relacionamento que se processa unicamente por uma necessidade técnica da parturição, mediado por uma atitude mecanizada, demonstra o desinteresse do profissional para com as necessidades e direitos da parturiente, desrespeitando-a também em sua dimensão de ser em desenvolvimento e, por isso, ainda mais vulnerável, o que contrapõe-se ao papel de conselheiro, substituto, recurso e líder. ${ }^{6}$ Neste entendimento, um estudo afirma que ao perceber a usuária somente como objeto do trabalho dos profissionais de saúde, as parturientes acabam não tendo suas necessidades sanadas, em especial no âmbito emocional. ${ }^{16}$ Os resultados encontrados demonstram que a postura dos profissionais e o tratamento dispensado às adolescentes foram, por vezes, ofensivos, indo de encontro às orientações do Ministério da Saúde, que, por meio do documento "Parto, aborto e puerpério: assistência humanizada à mulher", ${ }^{2}$ afirma que os comentários e atitudes desrespeitosas devem ser banidos do dia a dia dos serviços de saúde, assim como os julgamentos e atitudes preconceituosas sobre o comportamento reprodutivo das mulheres em qualquer faixa etária, a fim de erradicar práticas condenáveis e anti-éticas nos serviços.

A subjetividade dos sujeitos envolvidos neste processo, o preparo à vivência do mesmo e para o exercício da autonomia, são aspectos diretamente relacionados à satisfação com o relacionamento interpessoal que se processa. Assim sendo, a interação de forma satisfatória 
também permeia a flexibilidade dos profissionais de saúde para o exercício de suas ações ${ }^{15}$ e para assumir os diferentes papéis descritos por Peplau. ${ }^{6}$

Diante das diferentes posturas que o profissional pode assumir, a parturiente reagirá de maneira positiva ou negativa. Os sentimentos partilhados com os outros envolvidos no processo de nascimento lhe são bastante significativos. ${ }^{17}$ Partindo deste pressuposto, a democratização das relações interpessoais deve ser levada em conta para que haja humanização, sendo que esta depende, também, de mudanças nas relações cotidianas, dos serviços e sistemas de gestão. ${ }^{20}$ Não obstante, o profissional deve permitir-se assumir os devidos papéis ao longo das relações interpessoais, partindo do reconhecimento mútuo ao assumir o papel de estranho, perpassando as demais atuações ${ }^{6}$, e tornando as relações instrumento de humanização da assistência ao parto, não somente das adolescentes, mas de todas as mulheres.

Diante da análise do conjunto dos dados, a partir dos estudos existentes e sob o olhar da teoria de Peplau, ${ }^{6}$ evidenciou-se que o relacionamento interpessoal da equipe com a parturiente e seus acompanhantes não é compreendido por todos como parte fundamental da assistência. As falas revelam que, em muitas situações, os profissionais assumem os papéis descritos por Peplau ${ }^{6}$ de modo oportuno, enquanto outros não o fazem, o que comprova o caráter subjetivo e sem uniformidade das relações interpessoais durante o parto. Neste sentido, infere-se que os processos interacionais não estão sendo explorados em sua plenitude, como intrínsecos ao cuidado.

\section{Considerações finais}

Este estudo permitiu conhecer a percepção das adolescentes acerca das relações interpessoais que se processam com os profissionais de saúde durante a assistência ao parto, revelando perspectivas distintas dos processos interacionais, que podem trazem satisfação e insatisfação. Para algumas parturientes, o relacionamento interpessoal foi permeado por atitudes de respeito, paciência, cordialidade, solicitude, presença constante, tranquilidade, 
19 I Biondi HS, Kerber NPC, Tavares DH, Pinho EC, Gonçalves-Griespach BG, Marques LA

calma e partilha de informações, aspectos estes que revelam que os profissionais assumem, em diferentes momentos, os papéis descritos por Peplau. Este modo de atuação permite que sejam acolhidas e sanadas as necessidades psicoemocionais das adolescentes, em suas singularidades trazidas pela faixa etária.

Todavia, o contrário também transpareceu em muitos depoimentos, com o relacionamento marcado pelo distanciamento, desinformação, desrespeito e hostilidade, desconsiderando as necessidades pscioemocionais que são trazidas pela pouca maturidade destas mulheres. A forma utilizada pelos profissionais para comunicar-se com as parturientes, bem como sua postura durante o processo de parturição configuram-se em situações nas quais a relação interpessoal se processa de forma insatisfatória para as adolescentes.

A insatisfação das parturientes na relação com os profissionais de saúde parece estar ligada à falta de empatia na esfera de cuidado, a especificidade da postura adotada por cada profissional e pela pouca ou nenhuma interação entre eles e as adolescentes. Outro aspecto relevante está posto no fato de que as relações interpessoais no ambiente do estudo se processam predominantemente durante a realização dos procedimentos técnicos, desvalorizando as particularidades da parturição na adolescência e permitindo o afloramento e a potencialização de medos, anseios e angustias, significativamente danosos a evolução do parto e aos saldos desta vivência à mulher, criança e família.

A coleta de dados durante a internação pode favorecer a enunciação de detalhes fidedignos aos vivenciados. Porém, cabe a ressalva que este momento também é permeado de grande vulnerabilidade e intensas demandas emocionais, somadas a fragilidade inerente a pouca idade, podendo influenciar no conteúdo trazido nas falas devido ao receio de efetuar colocações acerca da assistência enquanto no ambiente hospitalar.

Para construir uma assistência humanizada ao parto, faz-se necessário que os profissionais de saúde do CO percebam que o cuidado envolve aspectos emocionais, sociais e 
culturais, e não apenas aspectos técnicos. Esta percepção é imprescindível para uma assistência humanizada e, é nesse sentido, que se cogita que há um longo caminho a ser percorrido no hospital em estudo, tendo como pontos reflexivos os relatos que sinalizam para as relações interpessoais satisfatórias.

Acredita-se que seja necessária a reflexão coletiva sobre o verdadeiro significado de humanizar a assistência ao parto, abarcando as subjetividades que cercam as relações interpessoais que se materializam durante a vivência de tornar-se mãe, permeada de simbolismos e acepções, especialmente na multidimensionalidade da adolescência. Torna-se essencial a verdadeira valorização dos sentimentos, anseios e expectativas das parturientes, para além da mecanização dos atos inclusos na prática assistencial dita humanizada.

\section{Referências}

1. Ferreira LA, Silva JAJ, Zuffi FB, Mauzaito ACM, Leite CP, Nunes JS. Expectativa das gestantes em relação ao parto. Rev Pesqui Cuid Fundam [Internet]. 2013 abr-jun [acesso em 2017 set 16];5(2):3692-7. Disponível em: http://www.seer.unirio.br/index.php/cuidadofundamental/article/view/2057/pdf_758.

2. Brasil. Ministério da Saúde. Humanização do parto e do nascimento. Rede Humaniza SUS. Brasília (DF): Ministério da Saúde; 2014. [acesso em 2017 set 14]. Disponível em: http://www.redehumanizasus.net/sites/default/files/caderno_humanizasus_v4_humanizacao_parto.pdf.

3. Ribeiro JF, Machado PHM, Araújo KRS, Sepúlvedra BA. Assistência ao parto normal sob o olhar da parturiente. Rev Eletrônica Gest Saúde [Internet]. 2016 [Acesso em 2017 out 02];7(1):113-25. Disponível em: http://periodicos.unb.br/index.php/rgs/article/view/22070/15764.

4. Silva RC, Soares MC, Jardim VMR, Kerber NPC, Meincke SMK. Discurso e a prática do parto humanizado de adolescentes. Texto \& Contexto Enferm [Internet]. 2013 jul-set [acesso em 2017 ago 05];22(3):629-36. Disponível em: http://www.scielo.br/scielo.php?script=sci_arttext\&pid=S0104-07072013000300008.

5. D’Orsi E, Brüggemann OM, Diniz CSG, Aguiar JM, Gusman CR, Torres JA, et al. Desigualdades sociais e satisfação das mulheres com o atendimento ao parto no Brasil: estudo nacional de base hospitalar. Cad Saúde Pública [Internet]. 2014 [acesso em 2017 set 02];30(Supl 1):S154-S168. Disponível em: http://www.scielo.br/scielo.php?pid=S0102-311X2014001300021\&script=sci_abstract\&tlng=pt.

6. Peplau HE. Interpersonal Relations in Nursing: a conceptual frame of reference for psychodinamic nursing. New York: Springer Publishing Company; 1991. 
7. Braga TL, Santos SCC. Parto humanizado sob a ótica da equipe de enfermagem do Hospital da Mulher Mãe Luzia. Rev Eletrônica Estácio Saúde [Internet]. 2017 [acesso em 2017 dez 18];6(1):20-33. Disponível em: http://revistaadmmade.estacio.br/index.php/saudesantacatarina/article/view/3641.

8. Caires TL, Santos RS. O saber da enfermagem obstétrica e suas contribuições sociais para a autonomia da parturiente. Rev Enf Prof [Internet]. 2014 jul-dez [Acesso em 2017 ago 30];1(2):422-35. Disponível em: http://blog.educare.bio.br/wordpress?p=2437.

9. Trindade DFS, Spinielli MAS, Moreira BD. Modelos da comunicação no processo de humanização do parto e nascimento em uma maternidade de Mato Grosso, Brasil. Rev Bras Pesqui Saúde [Internet]. 2018 [acesso em 2018 nov 28];20(2):44-53. Disponível em: http://www.portaldepublicacoes.ufes.br/RBPS/article/viewFile/21231/14145.

10. Bardin L. Análise de conteúdo. São Paulo: Edições 70; 2011. Organização da Análise; p. 125-132.

11. Silva ALA, Mendes ACG, Miranda GMD, Souza WV. A qualidade do atendimento ao parto na rede pública hospitalar em uma capital brasileira: a satisfação das gestantes. Cad Saúde Pública [Internet]. 2017 [acesso em 2017 dez 28];33(12):1-13. Disponível em: http://www.scielo.br/scielo.php?pid=S0102311X2017001205003\&script=sci_abstract\&tlng=pt.

12. Baracho VS, Caldeira ABR, Guedes CF, Ferreira PHC, Guedes HM, Ribeiro LCC. Visão dos clientes externos sobre a satisfação dos serviços de enfermagem hospitalar: abordagem interpessoal. Rev Eletrônica Gest Saúde [Internet]. 2016 [acesso em 2017 out 21];7(2):608-22. Disponível em: periodicos.unb.br/index.php/rgs/article/download/3513/3199/.

13. Camacho KG, Progianti JM. A transformação da prática obstétrica das enfermeiras na assistência ao parto humanizado. Rev Eletrônica Enf [Internet]. 2013 [Acesso em 2017 set 12];15(3):648-55. Disponível em: https://revistas.ufg.br/fen/article/view/18588/15490.

14. Silva IA, Silva PSF, Andrade EOF, Morais FF, Silva RSS, Oliveira LS. Percepção das puérperas acerca da assistência de enfermagem no parto humanizado. Rev Uningá [Internet]. 2017 jul-set [Acesso em 2017 out 21];53(2):37-43. Disponível em: https://www.mastereditora.com.br/periodico/20170806_102009.pdf.

15. Possati AB, Prates LA, Cremonese L, Scarton, J, Alves CN, Ressel LB. Humanização do parto: significados e percepções de enfermeiras. Esc Anna Nery Rev Enferm [Internet]. 2017 ago [acesso em 2017 out 12];21(4):1-6. Disponível em: http://www.scielo.br/scielo.php?script=sci_arttext\&pid=S1414$81452017000400203 \& \operatorname{lng}=$ en\&nrm=iso\&tlng=pt.

16. Faria SDA, Rodrigues MS. Programa educando para o bem nascer: implicações na qualidade da assistência ao pré-natal. Rev Bras Ciênc Vida [Internet]. 2017 [acesso em 2017 dez 28];5(2):1-27. Disponível em: http://jornal.faculdadecienciasdavida.com.br/index.php/RBCV/article/view/236.

17. Barboza LP, Mota A. Violência obstétrica: vivências de sofrimento entre gestantes do Brasil. Rev Psico Divers Saúde [Internet]. 2016 [Acesso em 2017 out 12];5(1):119-29. Disponível em: https://www5.bahiana.edu.br/index.php/psicologia/article/view/847. 
18. Franklin J, Bittar CM. A humanização do parto. Relatos de puérperas que tiveram parto normal em um hospital privado no município de Franca. Rev Investigação [Internet]. 2015 [acesso em 2017 out 01];14(2):13948. Disponível em: http://publicacoes.unifran.br/index.php/investigacao/article/view/865/748.

19. Sánchez SB. La violencia obstétrica desde los aportes de la crítica feminista y la biopolítica. Dilemata [Internet]. 2015 [acesso em 2017 set 19];7(18):93-111. Disponível em: http://www.dilemata.net/revista/index.php/dilemata/article/view/374.

20. Aguiar JM, D'Oliveira AFPL, Schraiber LB. Violência institucional, autoridade médica e poder nas maternidades sob a ótica dos profissionais de saúde. Cad Saúde Pública [Internet]. 2013 nov [acesso em 2017 dez 21];29(11):2287-96. Disponível em: http://www.scielo.br/scielo.php?pid=S0102311X2013001100015\&script=sci_abstract\&tlng=pt.

\section{Autor correspondente}

\section{Heitor Silva Biondi}

E-mail: enf.heitor@gmail.com

Endereço: Rua Roberto Socoowisk, no 757, casa 57, Rio Grande, Rio Grande do Sul, Brasil.

CEP: 96213002

\section{Contribuições de Autoria}

1 - Heitor Silva Biondi -

Contribuições nas fases de concepção; planejamento; obtenção, análise e interpretação dos dados; redação e revisão crítica.

2 - Nalú Pereira da Costa Kerber -

Contribuições nas fases de concepção; planejamento; obtenção, análise e interpretação dos dados; redação e revisão crítica.

3 - Diogo Henrique Tavares -

Contribuições nas fases de análise e interpretação dos dados e redação.

4 - Eliana Cardia de Pinho -

Contribuições nas fases de análise e interpretação dos dados; redação e revisão crítica.

5 - Bruna Goulart Gonçalves -

Contribuições nas fases de concepção; planejamento; obtenção dos dados. 
23 I Biondi HS, Kerber NPC, Tavares DH, Pinho EC, Gonçalves-Griespach BG, Marques LA

6 - Letícia Amico Marques -

Contribuições nas fases de interpretação dos dados; redação e revisão crítica.

\section{Como citar este artigo}

Biondi HS, Kerber NPC, Tavares DH, Pinho EC, Gonçalves-Griespach BG, Marques LA. Relações interpessoais durante o parto: percepções de adolescentes. Rev. Enferm. UFSM. 2019 [Acesso em: 2019 jun 15];vol ex:1-23. DOI:https://doi.org/10.5902/2179769231202 